\title{
Constructing disability in online worlds: conceptualising disability in online research
}

\author{
Diane Carr*
}

London Knowledge Lab, Institute of Education, University College London, London, UK

\begin{abstract}
In this paper the online construction of disability is investigated and the implications for educators working in virtual worlds are considered. Based on the analysis of data collected through interviews with deaf residents of Second Life, it is argued that research into online identity, disability and education needs to allow room for self-description, and that educators need to recognise the power relations that can lurk within practices of provision or accessibility support. Working through these issues involves reconciling disability studies with e-learning and accessibility perspectives. It is proposed that strategies that would support this reconciliation might be found in recent literature on disability and technology.
\end{abstract}

Keywords: virtual worlds; deaf; disability; identity; accessibility; technology

\section{Introduction}

Educators are increasingly interested in the teaching and learning potential of virtual worlds such as Second Life (Kirriemuir 2008). However, participation in virtual worlds may not be straightforward for disabled people. For example, during 2007 an integrated voice feature was introduced into Second Life by its developers, Linden Labs. Prior to the introduction of this voice feature most users (or 'residents') communicated by typed text-chat. With the arrival of the voice feature, some deaf residents found themselves suddenly excluded from relationships, groups and events. Of course, it was not the voice feature as tool that disabled these users, so much as the various practices and conventions that emerged in its wake.

To explore these matters interviews were conducted with deaf Second Life residents. The impact of the voice feature was investigated, and the construction of deafness as a disability in Second Life was examined. A major theme that emerged during analysis of the data was that of 'loss', which encompassed references to learning, adjustment and identity. The interviewees offered clarifications and revisions when discussing these issues. They were forthright and articulate about the impact of voice, yet wary of and resistant to being positioned as bereft or passive. These matters are explored using a cultural studies framework, while reference is made to literature from disability studies, deaf studies, Second Life and education research. These different literatures offer insights relevant to the topic, yet these approaches are not especially compatible, particularly in terms of the conceptualising of disability itself. This paper begins with a consideration of these differences.

\section{Disability and Second Life}

Residents of Second Life (or SL) who identify as disabled have been active in establishing facilities and social networks to welcome and support participation by disabled people (see http://

\footnotetext{
*Email: D.Carr@ioe.ac.uk 
virtualability.org). In addition to creating and contributing to these services, it is reasonable to assume that residents who experience real life $(R L)$ disability are spread across the general SL population, enjoying various aspects of this virtual world, creating content and contributing to its communities.

As yet little has emerged within the Second Life and education literature on the topic of disability. This study draws on relevant research into disability, deafness and new media (Goggin and Newell 2003), and deaf people's use of the Internet (Valentine and Skelton 2008; Guo, Bricout, and Huang 2005). Research on social aspects of Internet use by disabled people also informs this research (Seymour and Lupton 2004; Bowker and Tuffin 2004, 2003; Davidson 2008). When disability is mentioned in relation to SL there is a tendency to list the various modes of communication, socialising and mobility on offer in this virtual world, and to 'match' these offers to a corresponding set of real life impairments (see Boellstorff 2008, 137, I47). The ways in which SL might be rendered accessible to blind and visually impaired users has been researched (White, Fitzpatrick, and McAllister 2008), and educators interested in the inclusive potentials of Second Life have noted its capacity to support a range of learners due to its varied modalities (Sheehy 2008; Ball and Pearce 2008). It is important to recognise that the new voice feature may have made SL more accessible to some users, but it is also necessary to acknowledge that navigation and the interface may still present considerable difficulties.

While academic papers on SL, education and disability are still rare, disability is certainly discussed at blogs, on mailing lists, at educator's seminars in SL, and at real life SL and education events. In these contexts, disability tends to be discussed in terms of exemplar projects, special facilities or perhaps compensation ('Will using SL improve the life of disabled users?'); in terms of the development of tools to support participation, or in relation to compliance (educators' recognition of their legal responsibility to comply with legislation as regards disability and equal opportunities). This framing of the issues reflects e-learning and accessibility perspectives. For reviews of the literature in this area, see Kinsash, Crichton, and Kim-Rupnow (2004), Seale (2004).

A focus on accessibility is legitimate. Yet if the education and Second Life community adopts this perspective without deliberation, there is a risk that the central concepts (relating to identity and disability in online contexts, for example) will remain undertheorised. One such risk, for instance, involves the inadvertent propagation of an 'impairment as problem/technology as solution' dynamic. Such patterns implicitly define disability as a property of potentially marginalised individuals who are in need of special support. Research that frames disability in terms of individualised impairment (as a medical condition or tragic deficit, for example) has been soundly and exhaustively critiqued within disability studies (Oliver 1990). By contrast, a social model of disability (Barnes 2000) attends to the disabling aspects of an environment: as when cultural practices, assumptions, expectations or material phenomena assume a standardised or 'normal' body, and exclude or penalise those who deviate from this pattern (Davis 2006). Simi Linton describes disability studies as a distinct field involving humanities or interpretive social science research that conceptualises disability as cultural construct. Linton thus distinguishes between the 'socio-political-cultural examination of disability [and] the interventionist approaches that characterise the traditional study of disability' (Linton 1998, 525). According to Linton, a common feature of the later approach is a lack of reflection on the ways in which the disabled subject is conceptualised.

Various authors (Shakespeare 2006; Gronvik 2007) have critiqued the social model of disability for ignoring personal or practical aspects of disability - including researchers engaged with the development of tools to support accessibility and inclusion (Dewsbury et al. 2004). Educators active in SL may need to find a way to work between these perspectives: to address practical aspects of accessibility, without ignoring the social, political and cultural aspects of 
disability and online identity. Goggin and Newell have warned that research on disability and ICT is 'replicating charity, medical and other oppressive discourses of disability' as a result of a failure to engage with disability studies $(2006,310)$. Evidently this is a trap that educators and researchers working in Second Life should strive to avoid.

\section{Deaf in Second Life}

As the above suggests, disability can be variously conceptualised. So can deafness. It is possible, for example, to self-describe as upper-case 'Deaf' or lower-case 'deaf'. Being Deaf involves laying claim to a socio-linguistic and cultural affiliation and fluency in a sign language (Davis I995, 2007). A Deaf person living and working in a sign literate community would not be disabled (Ladd 2003). On the other hand, the term 'deaf' might be used simply to refer to a hearing loss. It does not express a specific degree or severity of hearing loss, so it arguably encompasses terms like 'hard of hearing' and 'hearing impaired'. All of these definitions are emotive and contested (Lane 2006; Grushkin 2003). In this paper the term 'deaf' will be used in a general, inclusive sense, except where the words Deaf or D/deaf appear in cited work or quotations. This is for the sake of simplicity and in recognition of the fact that some Deaf people whose first and preferred language is sign, and who have limited fluency in a second language such as English, may face problems when attempting to access SL or the Internet generally (Correll and Maruyama 2005).

The introduction of voice to SL was controversial (Carr and Oliver 2010) and the potential impact on deaf residents was noted. For example, in an short article published in Second Opinion (July 2007) a Linden Labs newsletter, titled 'Voice: Another valuable choice' SL's developers acknowledged the social ramifications of voice for deaf residents, while suggesting that the technology (and hence, presumably, the developers) are not accountable: 'While a deaf Resident may find him or herself excluded in some social contexts, their ability to communicate in SL, has not been diminished from a technical viewpoint'. Later in the article it is stated that: 'Most educators would agree that learning is better facilitated between individuals with voice' - a statement that 'normalises' the experience of hearing educators and students.

Considering the above in relation to literature on the cultural construction of difference, disability and deafness, such as Lennard Davis' (1995) Enforcing normalcy: Disability, deafness and the body, makes it possible to articulate some key points. Firstly, Davis argues that 'disabilities appear or are highlighted in environments that produce disability' (Davis 1995, 165). It is arguable that the voice feature within SL (or, at least, the take-up of this voice feature by residents) changed the manner in which deafness was produced in that particularly environment. If this is the case, then another point by Davis becomes relevant. He argues that:

In the task of rethinking and theorising disability, one of the first steps is to understand the relationship between a physical impairment and the political, social, even spatial environment that places that impairment in a matrix of meanings and significations. (Davis 1995, 3)

What is interesting is that the introduction of voice to SL involves a situation where the political and social environment changed due to a technological alteration, in a manner that had specific implications for those with a particular impairment. There were indications that, in some circles at least, voice would become the 'norm' and, as Davis argues (29), when a norm is constructed, so is deviation. Difference, in such a case, encounters a 'hegemony of normalcy' (44) that renders 'deviant' (or at least marginalises) particular identities.

Thinking about disability and education in online worlds solely in terms of tools that support participation may be insufficient. It is also necessary to look at the conventions that emerge in the wake of these tools, and the implications for online identity. Investigating these issues also 
involves thinking about how the disabled or deaf subject is constructed in and through research itself.

\section{Research strategy and methods}

As the above indicates, engaging with literature relevant to virtual worlds and deaf residents, disability and technology, while thinking about the implications for education, involves traversing several fields that are themselves multi-disciplinary. This multiplicity increases once issues of methodology are raised. Anthropological and ethnographic studies of online worlds and online communities (Boellstorff 2008; Taylor 2006) are relevant, as is earlier work on online identity (Turkle 1995) and 'virtual ethnography' as methodology (Hine 2000). A positive side-effect of field traversal is that it potentially destabilises the role of researcher-as-expert. Rather than approaching the job of research as an authority, he or she is compelled to grope beyond his/her 'comfort zone'. A second (less speculative) point to make about research that shifts between and across different fields, involves the need to clearly identify the conceptual framework on which the research is founded (Lesham and Trafford 2007). In this instance, the conceptual framework employed is that of cultural studies.

Cultural studies as 'a field of enquiry' (Gray 2003, 12) is compatible with disability and deaf studies. These fields share an interest in the construction of difference, discourse and issues of subjectivity, identity, power and reflexivity. Given the topic under investigation, the dynamic between researcher and informant is particularly sensitive. There are issues of responsibility in terms of ensuring a non-exploitive relationship to an online community (Ess et al. 2002). Additionally, there is a need to recognise the long history of exploitative relations between disabled people and scientific research, medical research and education (Branson and Miller 2002). Cultural studies often involves exploring people's investments in texts and practices, rather than the pursuit of large scale research, representative samples or generalisability. There is a focus on the relationships between text, practices and identity (Gray 2003, 15). Identity is often discussed in terms of subjectivity, which is 'made up of our positions in and encounters with particular discourses' (Gray 2003, 75). Cultural studies research tends to be modestly scaled (Gray 2003, 74). There were also practical limitations as regards the scale of this study. Voice rolled-out in August 2007 and these interviews were conducted in March 2009. Locating the resources to support a larger study would have resulted in further delay. The delay between the introduction of voice, and the interviews, was advantageous, however, in that it allowed for longitudinal perspective and reflection on the part of the interviewees.

To investigate the impact of the new voice feature on deaf residents, semi-structured interviews with residents who identify as deaf in their first or real lives were conducted. Interviewees were recruited from mailing lists and from within SL itself, through contacts, and through deaf groups. Within SL I used instant messenger (IM) and the search function to make contact with the leaders and founders of various deaf groups. These individuals acted as 'gate-keepers' (Wittel 2000) who volunteered to be interviewed, offered to circulate my request, or introduced me to potential interviewees. There was an element of 'snowballing', as the following quote from an interviewee suggests:

A resident of mine emailed me this morning all excited hearing about you from someone she wants to be interviewed too, lol, but could not be here at this time. ... Max is the one who told Zarya about you. She contacted me. (Treasure)

The recruitment was performed in English, which impacts on the sample. Five interviews were conducted, each lasting approximately an hour. The questions asked during the interviews involved experience and preferences in SL, the introduction of voice, the resident's recollections of the roll-out, and the subsequent impact of voice on their experiences in SL. 
My avatar met interviewees at a time and location of their choosing. To allow for informed consent, interviewees were handed a note-card within SL prior to the interview starting. The note-cards were prepared using the ethics guidelines produced by Ess and the AolR Committee (2002). On the card, various definitions were offered (of 'deaf' for example) and a commitment to the interviewee's privacy was affirmed. It was noted that pseudonyms would be used for all avatars, and that the interviews would be chat-logged. Interviewees were advised that minor changes (to spelling, for instance) might be made for the sake of clarity. As the researcher, I was identified in terms of relevant aspects of my real-life identity, including my deafness and my university affiliation. A link to my research blog was supplied. It was noted that the research is unfunded, and that the goal of the research was 'to contribute to and extend the debate on "disability" and identity within virtual worlds and in online communities'. Interviewees were asked to confirm in chat-text 'that you have read this note-card, and that you are happy for the interview to proceed'. Interviewees were advised that they were welcome to ask questions before, during or after the interview. All of the interviewees indicated their agreement, although one contributor, Treasure Ballinger, chose to be identified by her SL avatar. As she explained:

:) Thanks. I've read the notecard and agree, however I don't need to be anonymous. I advocate for deaf/Deaf/hard of hearing in $\mathrm{rl}$ [real life], and am on the rl board of Virtual Ability [in SL]. Not very anonymous anyway. No need to start now :)

The material collected through the chat-logged interviews totalled 30 pages of text. Analysis involved fragmenting the text and identifying clusters of meaning, or themes, that formed links and continuities across the data (Gray 2003, 148-8). To do this, the data was considered statement by statement. Initial codes were derived from these statements. The codes were then reviewed in order to identify any organising or structuring themes. By these means, a set of categories was developed. For example, 'loss', as an umbrella category, encompassed references to adjustment and change, identity, risk, privacy, learning and role. The level of attention directed by the interviewees themselves to particular issues (where attention was marked by qualifying statements, repetition, or emphasis by emote, for example) was regarded as significant. Later in the process, respondent validation was sought: the interviewees were invited to read through an early version of this paper (Gray 2003, 72). Two of the interviewees offered additional clarifications at that point.

This focus on the statements generated at the interviews did mean that other aspects of the interviews (as event or experience) were not considered. For example, each of the interviewees expressed aspects of their identity or tastes through the look (shape, species, gender, skin, hair, etc) of their avatar. Additionally, each of the interviewees chose to meet me in a space of their own (a garden, a room, a gallery, for example). This account does not incorporate these phenomena. One reason for this is that I suspect it would be difficult to connect an analysis of an avatar's hair or wardrobe to the issues at the centre of this study. Additionally, describing a participant's SL home in any detail would be likely to undermine their anonymity. The representation or overview of the material from the interviews that follows reflects the aforementioned focus on the emergent category of 'loss', with references to adjustment, learning, change, role and identity.

\section{The interviews}

The five interviewees quoted in this section are Treasure, Max, Anna, Zarya and Grace. These are pseudonyms, apart from Treasure who (as explained) preferred to be identified by her SL avatar. Anna had been resident in SL the longest, at four years. The interviewees were 
experienced, land-owning SL residents. Depending on their interests, they worked in SL (providing a service, developing tools or teaching classes, for example), built facilities, founded organisations, maintained friendships and/or engaged in various forms of play.

All of the interviewees had an opinion about the introduction of the voice feature, but the intensity of feelings as regards these changes definitely varied. Most reported that voice had negatively impacted on their SL social lives. As Max explained, it can be 'an issue when I'm in areas where people are socialising, using voice' in which case, the 'biggest problem of course is feeling left out'. Max moved away from certain areas, and 'drifted away from that circle of friends' - and continued to enjoy SL. Grace was much more emphatic about the negative impact of voice ('oh hell I was angry'), while Zarya made reference to people, groups, activities and areas that are no longer accessible. She described these changes in terms of loss, as well as adjustment and learning.

I think l've gotten to the point where I can safely avoid the Voice issue. Become more SL savvy, I don't know! LOL... I've had to adjust and work around [voice]. I enjoy SL, but l've had to enjoy it differently... I've given up trying to belong to poetry groups. And I don't go to the clubs anymore.

Treasure admitted to losing at least one friend to voice, and was clear that the impact of voice on some deaf residents should not be underestimated: 'Standing around, socially isolated while people chat around you in voice is at the very least uncomfortable'. Treasure was initially 'militantly' or even 'rabidly' anti-voice, but reports that her experiences as a disabilities advocate in SL have brought on a change in perspective: 'If I had to type with my feet, l'd want to be able to use voice also'.

In addition to having different perspectives on voice in SL, the interviewees had different experiences of deafness. All were fluent in written English. Treasure, Max and Grace are also fluent in ASL (American Sign Language). All were accustomed to explaining themselves in particular ways in different contexts while contending with various assumptions, as when Treasure notes that 'nothing is more annoying to me than to have a hearing person say, "treasure you are deaf? but you speak so well!” lol - it's actually insulting!' Remarks about self-definition incorporated references to shyness, different aspects of deaf identity, connections with a Deaf community, and negotiations with the hearing world:

Hmmm... it's pretty obvious I have a hearing loss in RL. I speak and lipread though, so sometimes I can get away without having to (like paying for groceries, pumping gas, etc etc). I describe myself as deaf (lower case d) [because] I never learned sign language, so I don't consider myself part of the Deaf culture. And, if I say 'hearing impaired' people assume I can use the phone (which I can't.) It's easier and more accurate for me to say l'm deaf. (Zarya)

Furthermore, as Treasure explained, some 'people are mean about deaf using type chat and not liking voice'. At times this hostility is rooted in hearing residents' disbelief, and their assumption that continued text use involves a wish to conceal a RL gender. Zarya referred to an incident where she had been pressed to explain her use of text to another resident. He had then coaxed information from Zarya about her experience of deafness, while acting 'fascinated and enraptured'. She discovered later that he had logged and shared this conversation with others ('I was really upset... I don't talk about [that] in detail to anyone... and I haven't since'). However, after relating the incident Zarya smiled (by emote), and described it as 'all part of the SL learning experience' (for research on risk, disability and online identity see Seymour and Lupton 2004; Bowker and Tuffin 2003).

Treasure is involved in education and advocacy, and Anna's job involves developing tools and sites for educators. Anna has experienced instances where students enrolled in her classes in SL left after discovering her use of text-chat, despite her having explained her preference for text in terms of her deafness. 
At the same time, Anna wanted to make it clear that she has 'presented at a few conferences in SL [using] text chat, and the organisers have always been supportive of that'. I contacted Anna again after the interview to ask if it would fair to say 'that at least some of the people who leave your classes because of voice preference, are educators in [SL and RL]?' which she confirmed. Anna's experience suggests that educators might not be any more sensitive as regards issues of inclusion or disability than the general SL population. When interviewees were asked if the wider SL community had been supportive or understanding of the impact of voice on deaf residents, Zarya remarked that 'Quite honestly, I don't think the general SL community had ANY idea', while Treasure responded 'Supportive of us? Not at all. still aren't really, much. A little better but not much'.

\section{Analysis}

The arrival of the voice feature had ramifications for these interviewees in terms of their online identity. Analysis of the interview data led to the identification of 'loss' as a significant theme. What is clear, however, is that 'loss' does not simply involve a deficit. Rather, loss was discussed in terms of an (admittedly unwelcome) change; a negotiation, and strategies of adjustment. The negative aspects of loss involved being 'outed' as deaf in a new context, the explanations (and exposure) that this entailed, and sudden exclusion from friendships, conversations and events. Yet there were repeated instances where reference to such losses was followed by a qualifying or clarifying comment. For example, Anna talks about students leaving her class but saw it as important to balance this by acknowledging the supportive attitudes shown by some conveners of SL and education events. Max referred to being left out, and changing his SL companions, but when I asked if 'voice could be said to have cost you friends', he responded 'well, I wouldn't put it that way. Not so strongly. But it's caused me to shift a little, yeah'. The point is not that some responses to the introduction of voice are laudable or positive, and others are less so. What is important is that the interviewees acted to 'make a space' when discussing these issues; to shift and reframe their references to loss and the management of loss, while articulating it or qualifying it in various ways.

During the interview participants made use of a wide range of elements when defining their deafness. These include sign language fluency, pride, and their relationship to Deaf Culture - as well as references to medical history, work life, family, preferences within SL and personality traits (such as shyness). This ability to fluently define this aspect of their identity (deafness) from a range of perspectives, using a variety of indicators, suggests that these subjects are accustomed to explaining themselves. As noted, the introduction of voice made it necessary to 'come out' as deaf in SL. Max, Anna and Treasure did not consider this an issue in relation to their online identities, but Grace and Zarya certainly did. Grace commented: 'Isn't it awful? You have to carry a big sign and slap a label on yourself and people see you differently... over and over'.

Grace was the most emphatic about the impact of voice and the personal loss it entailed: 'Why bother staying in SL when I have to deal with barriers in RL [real life] as a deaf person?' Despite being fluent in ASL Grace does not feel strongly affiliated with a Deaf community and her real life experience of isolation was one reason why her disappointed following the introduction of the voice feature to SL was so acute. Her collaborators within SL gradually shifted to voice use and as a consequence her leadership role within a particular organisation was diminished. She expressed vivid frustration and sadness in relation to these changes. She was contemplating leaving SL and voice was a contributing factor. Despite her colleagues well-intentioned efforts to include Grace (they apologised and tried transcribe or 'to type as fast as they could' while conversing), the voice feature and associated practices had proved disabling. 
Grace linked the voice feature to the disintegration of her leadership role. Role was an issue for several of the interviewees, who mentioned it in relation to the destabilisation that followed the introduction of voice. Treasure's experience suggests that role can be used to construct a viable oppositional identity; a position from which to actively resist the 'hegemony of normalcy' (Davis 1995, 44). Treasure's role within the SL community as advocate and activist provides her with a position to speak from. Perhaps the role of researcher functions similarly for the author. For another interviewee, Max, 'role' has particular implications because he is a keen role-player. These sociable and creative forms of play are popular in SL. Generally such games have a ruleset that is derived from Dungeons and Dragons style social games, although settings vary a great deal. Role-players develop a fictional identity and act in character, while collectively undertaking missions and intrigues. Role-players in virtual worlds often deliberately avoid using voice. It is too revealing of real life identity - and limited acting skills. Educators using role-play to teach in SL have also noted the limitations of voice (Addison and O'Hare 2008).

For some deaf residents, depending on their SL roles and preferences, voice might have had a relatively limited impact. For others, such as Grace, the impact has been more marked. Most of the interviewees made reference to the attempts of their hearing SL friends and colleagues to accommodate their use of text - but they also noted the limited success of these attempts (Max: 'a few will try to type for me what's being said... but obviously it's too hard to keep up'). Of course it is important to appreciate attempts to be inclusive, but no matter how well intentioned such attempts are, they tend to position those involved as either provider or petitioner.

\section{Discussion}

The interviewees' careful articulation of loss as involving a process of adjustment and learning suggests the importance of the scope for self-description in this context. It suggests sensitivity to being positioned in particular ways (as passive, dependent or tragic, for example), and resistance to a reductive focus on impairment. This raises two points relevant to questions of online identity, disability and education: the evident importance of self-definition and selfdescription; and the need to be conscious of the power relationships embedded in attempts at provision.

In relation to this second point, consider the apparently determining nature of some technologies, institutional policies and services. Goggin and Newell write that there is a danger that 'People with disabilities are expected to cut their cloth to fit the temporarily able-bodied world, and its new media technologies'. They identify a paradox when they argue that 'in its desire for the same, inclusion always requires the "other" to stay in its niche' (2003, 149). Harlan Lane (citing R.A. Scott's work in The making of blind men) makes a related point when he argues that the 'uncooperative' client of support services, is the one who believes that 'he is basically fine' (Lane 2006, 82). Together these points suggest a scenario in which staff and students are compelled to experience disability in a manner that conforms to the 'accessibility support' that is provided.

Such scenarios indicate the benefit of greater levels of exchange between disability studies (with its focus on subjectivity), and research on accessibility and design (with its focus on tools and technology). What disability studies would bring to Second Life, e-learning and accessibility debates is an insistence that researchers consider the ways in which disability is conceptualised in their work. It would also involve educators working in virtual worlds having to consider the ways in which their practices 'normalise' certain identities. These practices include teaching, as well as peer/professional activities such as virtual events, conferences and seminars. 
The interviewees' interest in self-description, clarification, resistance and 'talking back' (hooks 1989) is significant. Without such capacity, subjects who are disabled in online contexts risk being positioned in particular ways. Disabled colleagues may face the unenviable choice of either participating in events in a partial, limited and conditional manner, or leaving. Both options are self-defeating. Each involves performing a marginalised identity; and this marginalisation in turn confirms the centrality and power of the 'normal'. This is why educators working in virtual worlds such as Second Life need strategies that make it possible to acknowledge the importance of developing tools to support inclusion (as per e-learning and accessibility research) without ceding the political and critical agenda of disability studies.

There are precedents within disability studies that suggest how such strategies might be developed. For example, Ingunn Moser (2006) has used actor network theory - or ANT (Law 1994; Latour 2005) to explore the relationships between subjects, disability, contexts and technologies. Likewise, Valentine and Skelton have used ANT to study deaf people's use of the Internet, arguing that adopting this approach entails acknowledging that 'society is produced in and through patterned networks of heterogeneous materials in which neither the properties of humans or non-humans are self-evident, rather they emerge in practice' (Valentine and Skelton $2008,47 I)$. An ANT approach is reconcilable with a cultural studies agenda and, interestingly, it is increasingly being applied by academics studying computer games and identity in educational contexts (Jenson and de Castell 2008). While there would be various limitations to be considered (as with any research strategy), this approach may offer us a way to reconcile the need to produce and evaluate tools, with the need to think about the ways in which social and cultural factors (including tools and practices) construct and perpetuate disability. Perhaps such an approach will enable us to work towards a 'roomier', better contextualised, more responsive conceptualisation of disability in education and virtual world research.

\section{Conclusion}

Here, again, are Linden Labs comments on deaf people, the introduction of the voice feature and education: 'While a deaf Resident may find him or herself excluded in some social contexts, their ability to communicate in SL, has not been diminished from a technical viewpoint'. At the crux of this statement is recognition that exclusion is socially determined in online worlds - although various degrees of accessibility will be supported or undermined by different technological features. It might well be the case that 'Most educators would agree that learning is better facilitated between individuals with voice', as Linden Labs have claimed. It may be that new technical features will become available, equipping us to counter-act the potentially excluding practices found in various social, educational and professional contexts within SL. It is certainly the case that virtual worlds present us with an opportunity to rethink educational practices, including those that relate to inclusion (Sheehey 2008). We do not have to replicate the conventions and limitations of the real-world.

The research described in this paper has shown that deafness as disability is reproduced in virtual worlds, through discourse and practice. This suggests that identity within online worlds should be regarded as collaboratively constructed, and that the dynamics and resources that underpin and impact on these constructions are carried into virtual worlds from our everyday lives. There is nothing new about the exclusionary practices experienced by disabled residents in SL. However, online worlds and their various communities do demonstrate in new, clear ways, just how pervasive inequitable practices and discourses can be, and how difficult it can be to articulate and hence resist the power relations that are embedded within, and disseminated by, these same practices. Educators with an interest in equality, online learning, inclusion and technology cannot afford to overlook the implications. 


\section{Notes on contributor}

Diane Carr is Lecturer in Media and Cultural Studies at the Institute of Education, University of London. Her research interests include digital games, gaming cultures and online worlds, especially in relation to issues of subjectivity, representation and learning. More information about her publications, teaching and research can be found at http://playhouse.wordpress.com/.

\section{References}

Addison, A., and L. O'Hare. 2008. How can massive multi-user virtual environments and virtual role play enhance and embed with traditional teaching practice? Paper presented at ReLive08 Conference, November 20-21, at the Open University, Milton Keynes, UK.

Ball, S., and R. Pearce. 2009. Learning scenarios and workplaces with Virtual Worlds: Inclusion benefits and barriers of 'once-removed' participation. Paper presented at the ReLive08: Researching Learning in Virtual Environments conference, November 20-2I, at the Open University, Milton Keynes, UK.

Barnes, C. 2000. The social model of disability: A sociological phenomenon ignored by sociologists? In The disability reader: Social science perspectives, ed. T. Shakespeare, 65-78. London: Continuum.

Boellstorff, T. 2008. Coming of age in SL: An anthropologist explores the virtually human. Princeton: Princeton University Press.

Bowker, N., and K. Tuffin. 2003. Dicing with deception: People with disabilities' strategies for managing safety and identity online. Journal of Computer Mediated Communications 8, no. 2. http:// jcmc.indiana.edu/vol8/issue2/bowker.html.

Bowker, N., and K. Tuffin. 2004. Using the online medium for discursive research about people with disabilities, Social Science Computer Review 22, no. 2: 228-4I.

Branson, J., and D. Miller. 2002. Damned for their difference: The cultural construction of deaf people as disabled. Washington: Gallaudet University Press.

Carr, D., and M. Oliver. 20I0. Second Life, immersion and learning. In Social computing and virtual communities, ed. P. Zaphiris and C.S. Ang, 205-21. Boca Raton, FL: Chapman and Hall/CRC.

Correll, J., and T. Maruyama. 2005. Deaf people: Fact sheet no. 3. Project output. http://www.geog. leeds.ac.uk/projects/deafweb/.

Davidson, J. 2008. Autistic culture online: Virtual communities and cultural expression on the spectrum. Social \& Cultural Geography 9, no. 7: 791-806.

Davis, L.J. 1995. Enforcing normalcy: Disability, deafness and the body. London: Verso.

Davis, L.J. 2006. Constructing normalcy: The bell curve, the novel, and the invention of the disabled body in the nineteenth century. In The disability studies reader, ed. L.J. Davis, 3-16. New York: Routledge.

Davis, L.J. 2007. Deafness and the riddle of identity. The Chronicle of Higher Education January 12. http:// seattlecentral.edu/faculty/nwilso/ASL202/Define_deafness.pdf.

Dewsbury, G., K. Clarke, D. Randall, M. Rouncefield, and I. Sommerville. 2004. The anti-social model of disability. Disability and Society 10, no. 2: 145-58.

Ess, C., and the AolR Ethics Working Committee. 2002. Ethical decision-making and internet research. Recommendations from the AolR Ethics Working Committee. www.aoir.org/reports/ethics.pdf.

Goggin, G., and C. Newell. 2006. Editorial comment: Disability, identity and interdependence: ICTs and new social forms. Information, Communication and Society I 9, no. 3 June: 309-I I.

Gray, A. 2003. Research practice for cultural studies. London: Sage.

Gronvik, L. 2007. The fuzzy buzz word: Conceptualizations of disability in disability research classics. Sociology of Health and Illness 29, no. 5: 750-66.

Grushkin, D.A. 2003. The dilemma of the hard of hearing within the US deaf community. In Many ways to be deaf, ed. L. Monaghan, C. Schmaling, K. Nakamura, and G.H. Turner, II4-40. Washington: Gallaudet University Press.

Guo, B., J.C. Bricout, and J. Huang. 2005. A common open space or a digital divide? A social model perspective on the online disability community in China. Disability and Society 20, no. I: 49-66.

Hine, C. 2000. Virtual ethnography. London: Sage.

hooks, b. 1989. Talking back. Boston: South End.

Jenson, J., and S. de Castell. 2008. Theorizing gender and digital gameplay: Oversights, accidents and surprises. Eludamos. Journal for Computer Game Culture 2, no. I: I5-25.

Kinash, S., S. Crichton, and W.S. Kim-Rupnow. 2004. A review of the 2000-2003 literature at the intersection of online learning and disability. American Journal of Distance Education I5, no. 19: 5-19.

Kirriemuir, J. 2008. A spring 2008 'snapshot' of UK higher and further education developments In Second Life. http://www.eduserv.org.uk/foundation/sl/uksnapshot052008. 
Ladd, P. 2003. Understanding deaf culture. Clevedon: Multilingual Matters.

Lane, H. 2006. Construction of deafness. In The disability studies reader, ed. L.J. Davis, 79-92. New York: Routledge.

Latour, B. 2005. Reassembling the social: An introduction to actor-network-theory. Oxford: Oxford University Press.

Law, J. 1994. Organising modernity. Oxford: Blackwell.

Lesham, S., and V. Trafford. 2007. Overlooking the conceptual framework. Innovations in Education and Teaching International 44, no. I: 93-105.

Linden Labs. 2007. Voice: Another valuable choice. Second Opinion. http://secondlife.com/newsletter/ 2007_07/awsi.html.

Linton, S. 1998. Disability studies/not disability studies. Disability and Society 13, no. 4: 525-40.

Moser, I. 2006. Disability and the promises of technology. Information, Communication and Society 9, no. 3: 373-95.

Oliver, M. 1990. The politics of disablement. Basingstoke: Palgrave Macmillan.

Seale, J. 2004. The development of accessibility practices in e-learning: An exploration of communities of practice. ALT-J, Research in Learning Technology 12, no. I: 5I-63.

Seymour, W., and D. Lupton. 2004. Holding the line online: Exploring wired relationships for people with disabilities. Disability and Society 19, no. 4: 291-305.

Shakespeare, T. 2006. The social model of disability. In The disability studies reader, ed. L.J. Davis, 197-204. New York: Routledge.

Sheehy, K. 2008. Virtual environments: Issues and opportunities for developing inclusive educational practices. Paper presented at ReLive08 Conference, November 20-21, at the Open University, Milton Keynes, UK.

Taylor, T.L. 2006. Play between worlds. Cambridge, MA: MIT Press.

Turkle, S. 1995. Life on screen: Identity in the age of the internet. London: Weidenfeld and Nicolson.

Valentine, G., and T. Skelton. 2008. Changing spaces: The role of the internet in shaping deaf geographies. Social and Cultural Geography 9, no. 5: 469-85.

White, G.R., G. Fitzpatrick, and G. McAllister. 2008. Toward accessible 3D virtual environments for the blind and visually impaired. In Proceedings of the 3rd international Conference on Digital interactive Media in Entertainment and Arts (Athens, Greece, September 10-12, 2008). DIMEA '08, vol. 349. New York, NY: ACM.

Wittel, A. 2000. Ethnography on the move: From field to net to internet. Forum: Qualitative Social Research I, no. I. http://www.qualitative-research.net/index.php/fqs/article/viewArticle/I I3I/25 I7. 